\title{
Insights into Activity of Zoo Housed Asian Elephants (Elephas maximus) during Periods of Limited Staff and Visitor Presence, a Focus on Resting Behaviour
}

\author{
Katherine Finch, Fiona Sach (D), Malcolm Fitzpatrick and Lewis J. Rowden *
}

check for

updates

Citation: Finch, K.; Sach, F.;

Fitzpatrick, M.; Rowden, L.J. Insights

into Activity of Zoo Housed Asian

Elephants (Elephas maximus) during

Periods of Limited Staff and

Visitor Presence, a Focus on Resting Behaviour. J. Zool. Bot. Gard. 2021, 2, 101-114. https://doi.org/10.3390/ jzbg2010008

Academic Editor: Katherine A. Cronin

Received: 29 January 2021

Accepted: 12 March 2021

Published: 16 March 2021

Publisher's Note: MDPI stays neutral with regard to jurisdictional claims in published maps and institutional affiliations.

Copyright: (c) 2021 by the authors. Licensee MDPI, Basel, Switzerland. This article is an open access article distributed under the terms and conditions of the Creative Commons Attribution (CC BY) license (https:// creativecommons.org/licenses/by/ $4.0 /)$
Zoological Society of London, Outer Circle, Regent's Park, London NW1 4RY, UK; k.finch@chesterzoo.org (K.F.); fiona.sach@zsl.org (F.S.); malcolm.fitzpatrick@zsl.org (M.F.)

* Correspondence: lewis.rowden@zsl.org

\begin{abstract}
Historically, behaviour of zoo housed species during hours of limited staff and visitor presence has been poorly studied, largely due to the lack of appropriate technology. Advances in digital monitoring equipment and facility design by European elephant holders has given researchers scope to accurately evaluate behaviour for this species over $24 \mathrm{hrs}$. Various behavioural indicators of welfare have now been identified for zoo housed elephants; however the relationship between resting behaviour and welfare experience has been an area highlighted to require additional research. Lying rest is a potential positive welfare indicator for this species, with studies suggesting that engagement in lying rest can be used to monitor both psychological and physiological wellbeing. Throughout this work we aim to give insights into the behaviour of individual Asian elephants at ZSL Whipsnade Zoo, specifically between the hours of 16:00 and 10:00. In addition to presenting the activity budgets of our study individuals during these times, we explore individual engagement in resting behaviour. Furthermore, we evaluate the social associations of our study group during rest. We provide evidence that unrelated individuals can form strong associations with conspecifics when resting and show that life history is a factor to consider when evaluating social compatibility between group members. Finally, we demonstrate the positive role that calves and juvenile individuals can play in facilitating meaningful associations between group members during rest. Our study highlights the importance of evaluating behaviour during understudied time periods in order to obtain a holistic view of individual welfare, further emphasising the importance of adopting an evidence-based approach to management for this species in zoos.
\end{abstract}

Keywords: Asian elephant; resting; animal welfare; evidence-based management; social behaviour; sleep

\section{Introduction}

Modern zoos are striving to adopt a more holistic approach to assessing animal welfare [1], moving far beyond the requirements outlined in the "five freedoms" framework [2]. Zoos now aim to design habitats and management strategies which enable individuals to thrive in a zoo housed-environment [3]. Over the last two decades, criticisms have been raised in relation to the welfare experienced by elephants in European and North American zoos [4,5]. In consequence, a number of multi-institutional studies have been conducted, aiming to identify the relationship between zoo environmental factors and individual wellbeing [6]. Williams et al. [7] summarised that 37 unique indicators of welfare are used for African (Loxodonta africana) and Asian (Elephas maximus) elephants, which include documenting activity levels, recording engagement in positive social interactions, monitoring body condition scores, observing foot health and quantifying concentrations of faecal glucocorticoid metabolites. To evaluate individual wellbeing and welfare on an immediate and longer term basis, a range of these measures should be used simultaneously [7]. Carlstead et al. [8] show that meaningful elephant-keeper relationships are an important factor in the prediction of lower individual cortisol responses. Additionally, 
Edwards et al. [9] outlined that housing factors, such as free access to unique environments and management strategies including enrichment diversity, could influence the number of clinical heath events experienced by zoo housed elephants. Multi-institutional studies have also been conducted to understand how zoo environmental factors influence engagement in stereotypic behaviours, with Greco et al. [10] highlighting that variables such as isolated housing, experience of inter zoo transfers and time spent in mixed sex social groups influence engagement in stereotypy.

The social environment experienced by individuals is one of the key factors within a zoo setting to consider when evaluating welfare in elephants. When reporting the limited exposure of imported North American zoo housed elephants to birth experiences, PradoOveido et al. [11] outline the detrimental long-term welfare implications this could have for both those individuals and their offspring, due to limited opportunity to develop crucial allomothering skills [12].

Despite a focus in providing a more comprehensive overview of how different zoo environmental factors may influence overall welfare experience for elephants, there is a need for further information on the behaviour of individuals when there is a limited visitor and keeper presence, for example, outside of typical working hours. Due to recent advances in camera technology and increased investment by elephant holding zoos into facility design and monitoring equipment, robust evaluation of elephant behaviour over a $24 \mathrm{~h}$ period has become more achievable. $[13,14]$.

One of the most common behaviours observed in zoo housed animals during periods of limited staff and visitor presence is resting behaviour, with many species showing a circadian variation in activity [15]. Rest is essential to the development and maintenance of good health status in multiple species, including elephants [13]. However, resting has received little study in comparison to other more active behaviours, despite both genera of elephant being housed in zoos for over a century [16]. Santymire et al. [17] highlight that individuals can only experience rapid eye movement sleep, a phase of rest known for its important and restorative properties, when they are lying down. However, for a large herbivore such as an elephant, lying down increases their vulnerability to predation events [18]. As such, choosing to rest in a recumbent position could be suggested as an indication that individuals feel safe and comfortable within their environment. Duration of time spent in lying rest has been suggested, in Asian elephants, as an indicator of physiological health, with a low engagement in recumbent rest linked to poor foot and musculoskeletal health, particularly in geriatric individuals [19]. Additionally, the proportion of time that individuals spend lying down to rest can give an insight into psychological wellbeing, with a decrease in lying rest associated with poor group social compatibility [19]. The effect of changes in facility design or husbandry routine may also be evaluated using lying rest. The transition towards providing deep sand substrate to individuals was suggested to facilitate positive recumbent rest [20], particularly in individuals which previously showed a low engagement in this behaviour.

The aim of the study was to provide an insight into the activity of a female breeding group of Asian elephants housed at ZSL Whipsnade Zoo during time periods that are typically unobserved in a zoo setting, with a particular focus on evaluating resting behaviour. Our low cost, repeatable methods are designed to capture information on nocturnal behaviour alongside data on the duration, type and social context of rest behaviour. The information collected allows for a robust and comprehensive evaluation of individual wellbeing, during times of day where limited staff and visitor presence makes it difficult to observe animal behaviour. We aimed to highlight the importance of documenting this activity to obtain an accurate and holistic overview of individual wellbeing, emphasising the benefits of an evidence-based approach in the management of this species in a zoo setting. 


\section{Materials and Methods}

\subsection{Study Subjects}

The subjects of this research were five female Asian elephants housed at ZSL Whipsnade Zoo (WZ) UK, managed in a protected contact system. The breeding group consisted of two post reproductive females (AF1; Date of Birth [DOB]: 20 July 1982, AF2; DOB: 24 May 1982), one breeding adult female (AF3; DOB: 27 August 1998), one juvenile female (JF; DOB 23 July 2009) and one female calf (C; DOB 10 June 2016). Mother-calf dyads were present within the study group between "AF1" and "JF" and "AF3" and "C". "AF2" is an unrelated member of the study group but has been housed with "AF1" for over 30 years. Age classes for this study were determined using previous published work [6]. This group was one of two subgroups managed within the elephant facility at WZ, separated due to severe long-term incompatibility issues between two adult females. Our study group was housed with visual and auditory contact to another subgroup consisting of two individuals (one post reproductive cow and one young bull). An adult breeding bull was housed in a separate facility over $100 \mathrm{~m}$ away.

\subsection{Enclosure}

Housing provision was consistent throughout the entire duration of study. Study subjects were housed in a custom-built indoor facility totalling $700 \mathrm{~m}^{2}$, with multiple timed hay-nets, browse feeders and species-specific enclosure furnishings including enrichment devices. Individuals were housed on a fine grade sand substrate to a depth of at least 1 metre throughout the facility. Sand was maintained four times per week, providing a dynamic environment with sand mounds to facilitate lying rest for the study individuals. The times at which haynets were operated was regularly reviewed to ensure minimal disturbance to the individuals. Outside of the observed times as part of their normal daily management, all individuals had outdoor access to either all weather or grass paddocks, rotating seasonally over an area of approximately 7 acres.

\subsection{Data Collection}

Data were collected between 19 August 2018 and 28 February 2019 ( $n=139$ days), between the hours of 16:00 and 10:00 approximately, dependent on husbandry routines. Data were collected using instantaneous focal sampling (via closed circuit television (CCTV) recording) of state behaviours at 15 min intervals [21], for the entire duration that individuals spent in the habitat (Appendix A). Continuous focal sampling was used to record the precise duration of both standing and lying rest behaviour. Social aspects of resting behaviour were documented by recording the ID and proximity of the focal individuals two nearest conspecifics, in elephant body lengths, up to three elephant body lengths away [22]. An individual was only classed as engaging in social rest when the focal animal actively chose to rest in an area in which their conspecific/s were also resting. This data collection method along with the ability to pause and playback footage on the camera system, allowed for multiple individuals to be observed accurately across each observation period. Three CCTV cameras were used for recording behaviour; these were positioned to cover the entire indoor area with no blind spots. All data collection was carried out by the lead author, eliminating the need for interobserver reliability assessment. Observation time for the study totalled $2443 \mathrm{~h}$. For individuals "AF1", "AF2", "AF3" and "C" this equated to $450 \mathrm{~h}$ each or 25 nights total observation time. Due to "JF" being pregnant at the time of the study (estimated to give birth January 2019), more frequent observations were conducted on this individual. Total observation time for "JF" was $643 \mathrm{~h}$, or 35 nights. During the data collection period on 12 January 2019, "JF" gave birth to a calf which died $72 \mathrm{~h}$ later. As a result, data in date range 12 January-21 January 2019 was excluded from analysis for all individuals, as daily husbandry routines were severely disrupted during this period. Within the overall data collection period, data were classified into one of two seasonal conditions: "Summer" observation period was between 19 August 2018 and 3 
November 2018, “Winter" observation period was between 24 November 2018 and 28 February 2019.

\subsection{Data Analysis-Activity Budget}

All analyses were conducted using R statistical analysis software, version 1.3.1056 [23]. When tested for normality, activity budget data were found to have a normal distribution (Shapiro-Wilks test: Standing Rest; $\mathrm{w}=0.89, p=0.53$, Lying Rest; $\mathrm{w}=0.81$, $p=0.44$ ). Duration of resting behaviour, calculated in minutes, was also normally distributed ( $\mathrm{w}=0.98, p=0.24)$. In consequence, parametric statistical tests were used throughout data analysis. Due to the small sample size $(n=5)$ in this study, we treated each day as the experimental unit. When investigating the relationship between resting bouts and time spent resting, we treated each resting bout as the experimental unit. In both cases the authors accepted pseudoreplication. In consequence, we accept the inapplicability of our results to the wider zoo population of Elephas maxmius as a limitation of this particular analysis [21].

\subsection{Data Analysis-Social Data}

Sociograms were constructed using NetDraw network visualization software version 2.172 package on UCINET version 6.709 [24], using information obtained by calculating an Index of Association for each dyad within the study group [21]. Index of Association was used to determine the extent to which individuals within the study group associated with each other during the data collection period. Index of association score ranged from 0 (no association) to 1 (complete association), using the proximity data collected during periods of standing and lying rest for the focal individual. Only scores $\geq 0.1$ were displayed on the sociograms for clarity. Line thickness between nodes were adjusted to display the strength of relationships between individuals. To determine the true extent to which individuals were choosing to associate with each other during both lying and standing rest, sociograms were constructed only using data in which individuals were either touching or within one elephant body length of each other (the two closest proximity categories).

\section{Results}

\subsection{Activity Budgets}

Individual activity budgets were calculated for each of the study subjects. The most commonly observed behaviours for each animal were feeding (AF1: $65.8 \% \pm 1.9, \mathrm{AF} 2$ : $62.7 \% \pm 1.3$, AF3: $68.2 \% \pm 1.6$, JF: $57.9 \% \pm 0.93$, C: $37.9 \% \pm 3.7$; Figure 1) and resting (AF1: $26.4 \% \pm 1.7$, AF2: $24.1 \% \pm 0.9$, AF3: $23.0 \%, 1.3, \mathrm{JF}: 31.1 \% \pm 0.8, \mathrm{C}: 32.9 \% \pm 2.3)$; Figure 1 ). Individuals were not observed to engage in any stereotypic behaviour or agonistic social behaviour throughout this study. "Other" behaviours included positive social behaviour, enrichment manipulation, play and keeper interaction (Appendix A, Table A1). 


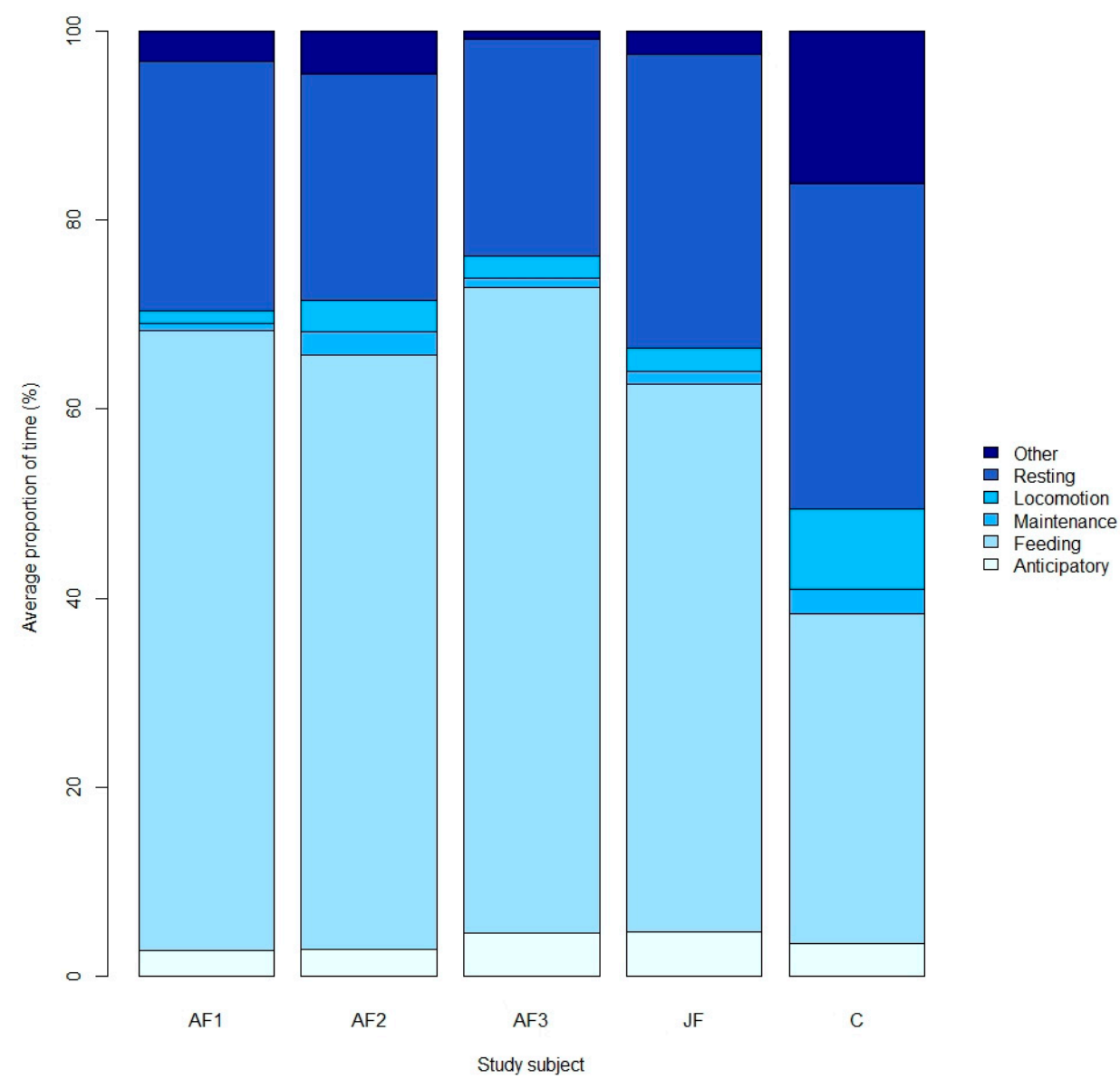

Figure 1. Activity budgets for each study subject, showing average proportion of time spent engaging in each behavioural category.

\subsection{Resting Times}

The data collection period was split into three six-hour time periods, in line with other published work [20].

The proportion of time spent engaging in standing rest did not significantly differ between time periods for four of the five study individuals (One way ANOVA: AF1: $\mathrm{F}=4.14, \mathrm{df}=24, p=0.06 ; \mathrm{AF} 2: \mathrm{F}=5.54, \mathrm{df}=24, p=0.12 ; \mathrm{AF} 3: \mathrm{F}=3.14, \mathrm{df}=24, p=0.23$; $\mathrm{JF}:=4.04, \mathrm{df}=34, p=0.10,-$ Table 1$).$ Throughout the data collection period, individual " $\mathrm{C}$ " spent all of her time in standing rest in "Period One" (One way ANOVA: $\mathrm{F}=38.43$, $\mathrm{df}=24, p<0.05$-Table 1 ).

Table 1. Proportion of time (\%) that each study subject spent engaging in standing and lying rest, throughout each period of the data collection window. Results presented as mean \pm s.e. * denotes a significant statistical difference to the other time periods.

\begin{tabular}{|c|c|c|c|c|c|c|}
\hline \multirow[b]{2}{*}{$\begin{array}{l}\text { Study } \\
\text { Subject }\end{array}$} & \multicolumn{2}{|c|}{$\begin{array}{l}\text { Period One } \\
(16: 00-22: 00)\end{array}$} & \multicolumn{2}{|c|}{$\begin{array}{l}\text { Period Two } \\
\text { (22:01-04:00) }\end{array}$} & \multicolumn{2}{|c|}{$\begin{array}{l}\text { Period Three } \\
\text { (04:01-10:00) }\end{array}$} \\
\hline & Standing & Lying & Standing & Lying & Standing & Lying \\
\hline AF1 & $45 \pm 1.9$ & $11 \pm 1.9$ & $12 \pm 3.2$ & $79 \pm 4.6^{*}$ & $43 \pm 4.8$ & $10 \pm 1.5$ \\
\hline AF2 & $51 \pm 5.8$ & $10 \pm 0.9$ & $23 \pm 2.2$ & $82 \pm 2.5^{*}$ & $26 \pm 6.1$ & $8 \pm 3.5$ \\
\hline AF3 & $45 \pm 1.9$ & $2 \pm 0.5$ & $32 \pm 2.1$ & $86 \pm 4.9 *$ & $42 \pm 3.9$ & $12 \pm 2.1$ \\
\hline $\mathrm{JF}$ & $45 \pm 3.2$ & $13 \pm 5.2$ & $19 \pm 2.9$ & $67 \pm 2.1^{*}$ & $36 \pm 1.2$ & $20 \pm 1.6$ \\
\hline C & $100 \pm 0$ * & $26 \pm 2.4$ & $0 \pm 0$ & $51 \pm 5.9^{*}$ & $0 \pm 0$ & $23 \pm 2.5$ \\
\hline
\end{tabular}


The proportion of time each study individual spent in lying rest did significantly differ between time periods (One way ANOVA: AF1: $\mathrm{F}=55.44, \mathrm{df}=24, p<0.05 ; \mathrm{AF} 2: \mathrm{F}=48.61$, $\mathrm{df}=24, p<0.05 ; \mathrm{AF} 3: \mathrm{F}=56.28, \mathrm{df}=24, p<0.05 ; \mathrm{JF}: \mathrm{F}=46.32, \mathrm{df}=34, p<0.05 ; \mathrm{C}: \mathrm{F}=51.30$, $\mathrm{df}=24, p<0.05-$ Table 1). Post hoc analyses with Bonferroni adjustment revealed that the pairwise differences between "Period One"-_"Period Two" and "Period Two"-_"Period Three" were statistically significant $(p<0.05)$, with all individuals spending the most time in lying rest at "Period Two" between the hours of 22:01 and 04:00 (Table 1).

\subsection{Seasonal Influences on Rest}

Study subjects were observed in "Summer" and "Winter" periods throughout the course of data collection. Duration of time spent resting (standing and lying rest combined) did not significantly differ for each individual between "Summer" and "Winter" data collection periods (Paired sample t-test: AF1: $\mathrm{t}=-1.18, \mathrm{df}=24, p=0.25 ; \mathrm{AF} 2: \mathrm{t}=1.82$, $\mathrm{df}=24, p=0.30 ; \mathrm{AF} 3: \mathrm{t}=2.89, \mathrm{df}=24, p=0.06 ; \mathrm{JF}: \mathrm{t}=0.75, \mathrm{df}=34, p=0.46 ; \mathrm{C}: \mathrm{t}=-1.85$, $\mathrm{df}=24, p=0.09$ (Figure 2).

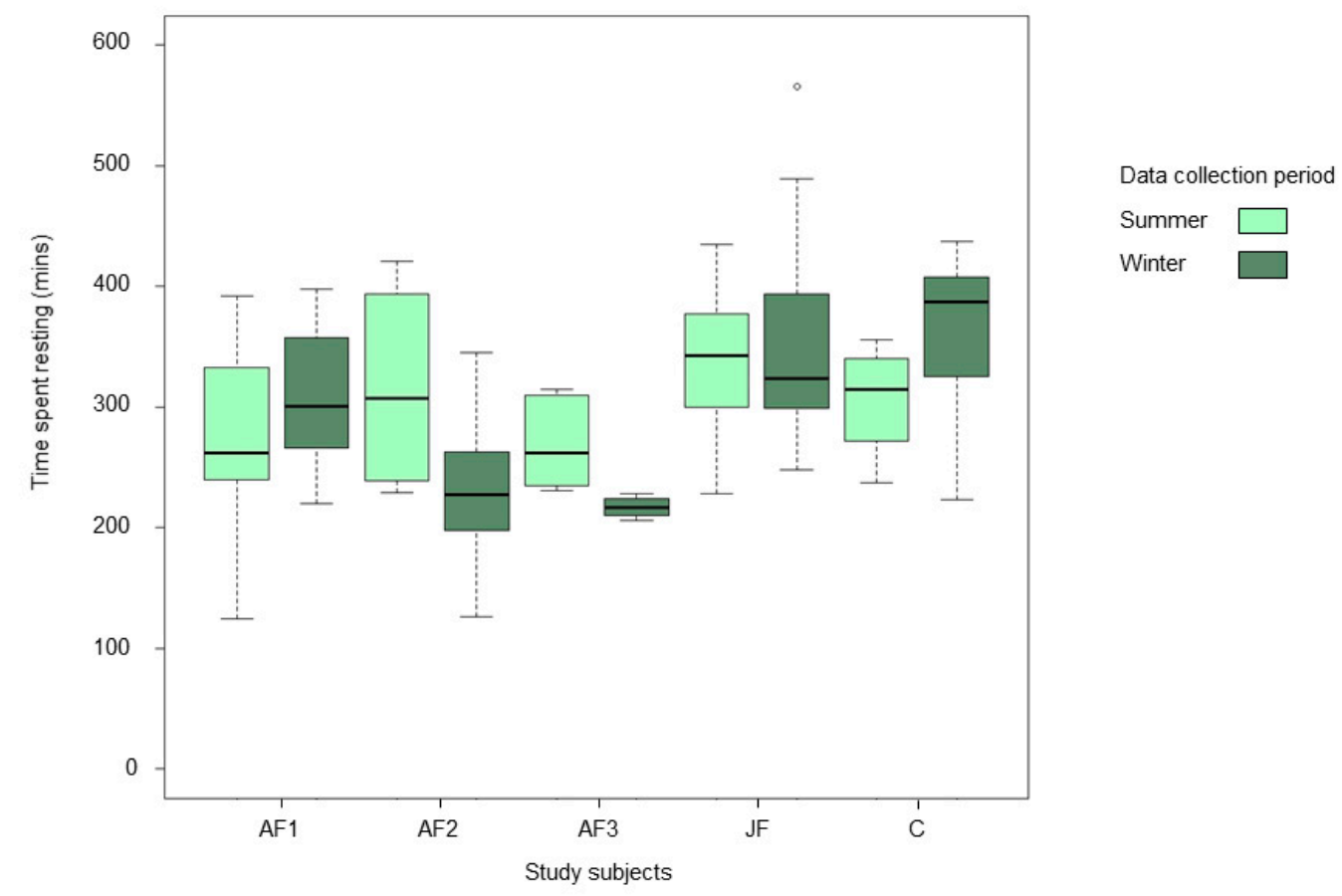

Figure 2. Total time spent resting (minutes), using both standing and lying rest data, for each study subject during the summer and winter data collection period. Data is displayed here as the median and interquartile range (IQR), with the whiskers representing Q1-1.5 * IQR and Q3 + $1.5 * I Q R$. Outliers are represented by the white circle.

\subsection{Relationship between Number of Rest Bouts and Total Time Resting}

For subjects within our study group, there was a strong positive correlation between the number of minutes spent in lying rest and the number of bouts of lying rest (Pearson's correlation: $\mathrm{t}=8.10, \mathrm{df}=289, p<0.001$, $c o r=0.637$ ). Additionally, we observed a strong positive correlation between the number of minutes spent in standing rest and the number of bouts of standing rest (Pearson's correlation: $\mathrm{t}=18.53, \mathrm{df}=289, p<0.001$, cor $=0.88$ ). When examining the relationship between lying and standing rest, we observed a negative correlation between the duration of time spent in lying rest and the duration of time spent in standing rest (Pearson's correlation: $t=-3.03, \mathrm{df}=289, p=<0.001$, cor $=-0.30$ ).

\subsection{Social Aspects of Resting Behaviour}

When evaluating the social aspects of resting behaviour, of their time spent in both lying and standing rest, all individuals studied chose to rest within two body lengths of 
a conspecific, doing so for over $80 \%$ of the time (Table 2). Three of the five individuals studied ("AF2", "JF" and "C") always chose to rest within two body lengths of a conspecific throughout our data collection period (Table 2). Three of the five individuals studied chose to spend the majority of their time resting either touching or within one body length of a conspecific (“AF1", “JF", “C"; Table 2).

Table 2. Proportion of time (\%) that each study subject spent touching a conspecific, within one elephant body length of a conspecific and within two body lengths of a conspecific when engaging in standing and lying rest.

\begin{tabular}{cccc}
\hline $\begin{array}{c}\text { Study } \\
\text { Subject }\end{array}$ & $\begin{array}{c}\text { Touching } \\
\text { Conspecific }\end{array}$ & $\begin{array}{c}\text { Within One Elephant Body } \\
\text { Length of Conspecific }\end{array}$ & $\begin{array}{c}\text { Within Two Body } \\
\text { Lengths of Conspecific }\end{array}$ \\
\hline AF1 & $3.3 \pm 1.9$ & $68.2 \pm 8.9$ & $97.4 \pm 2.6$ \\
\hline AF2 & $5.6 \pm 5.6$ & $45.3 \pm 13.2$ & $100 \pm 0$ \\
\hline AF3 & $33.2 \pm 7.6$ & $42.8 \pm 20.2$ & $80.1 \pm 10.6$ \\
\hline JF & $20.6 \pm 3.3$ & $85.2 \pm 4.6$ & $100 \pm 0$ \\
\hline C & $29.1 \pm 8.6$ & $63.1 \pm 11.9$ & $100 \pm 0$ \\
\hline
\end{tabular}

\subsection{Extent of Resting Associations}

3.6.1. Extent of Associations in Standing and Lying Rest

Dyads with the highest extent of association, during both standing and lying rest are "AF1" and "JF" (0.8), "JF" and "C" (0.6) and "AF1" and "AF2" (0.6; Figure 3).

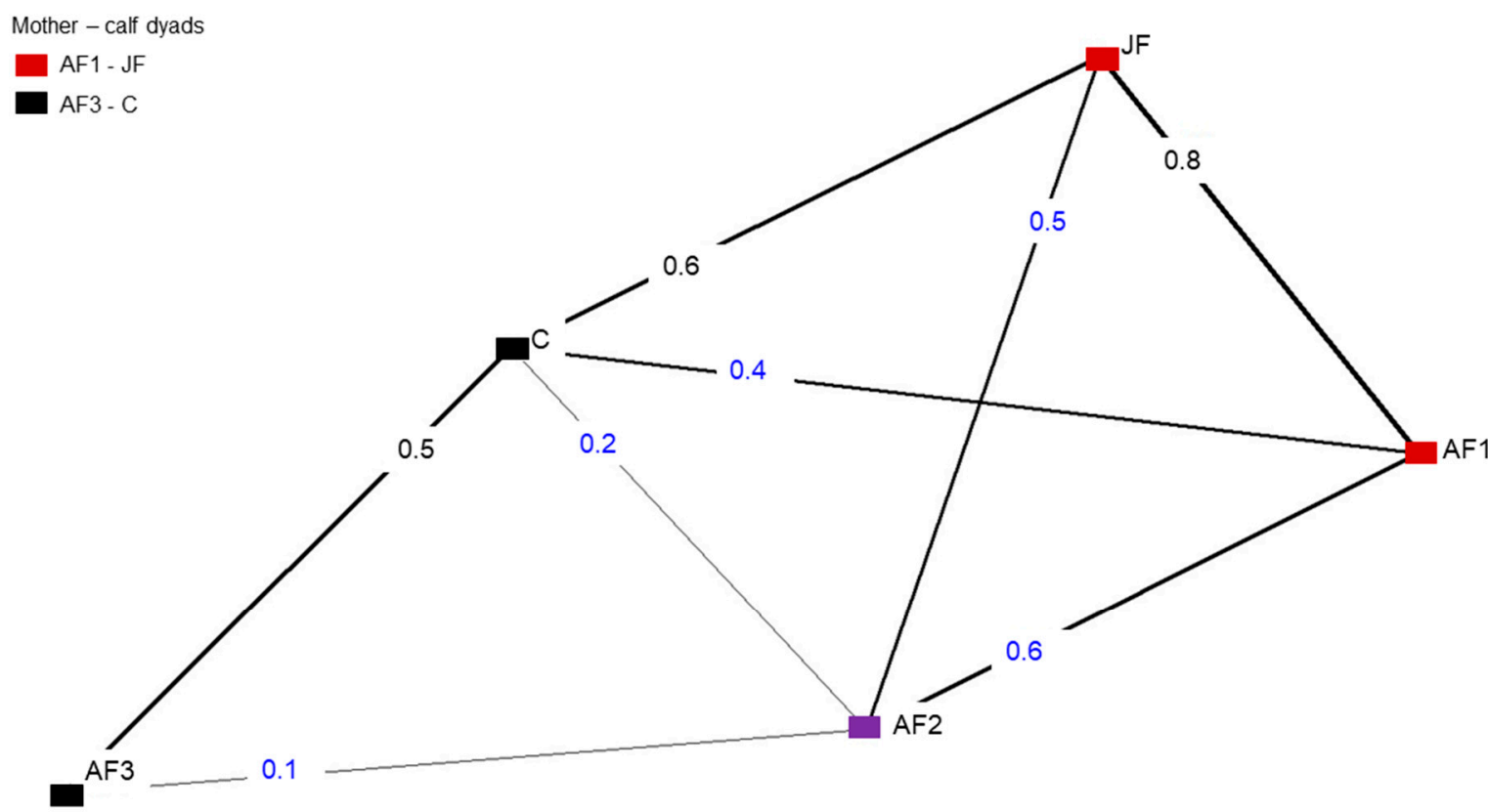

Figure 3. A sociogram highlighting the extent of association between study subjects, using both standing and lying rest data, when individuals were either touching or within one elephant body length of a conspecific. Only associations $\geq 0.1$ were shown on the sociogram for clarity. Matching node colours indicate a mother-calf dyad. Blue font denotes the extent of association between an unrelated dyad. Black font denotes the extent of association between a related dyad.

\subsubsection{Extent of Associations in Lying Rest Only}

Dyads with the highest extent of association, when in lying rest are "AF1" and "JF" (0.8), "JF" and "C" (0.6), "AF1" and "C' (0.6) and "AF1" and "AF2" (0.6; Figure 4). 


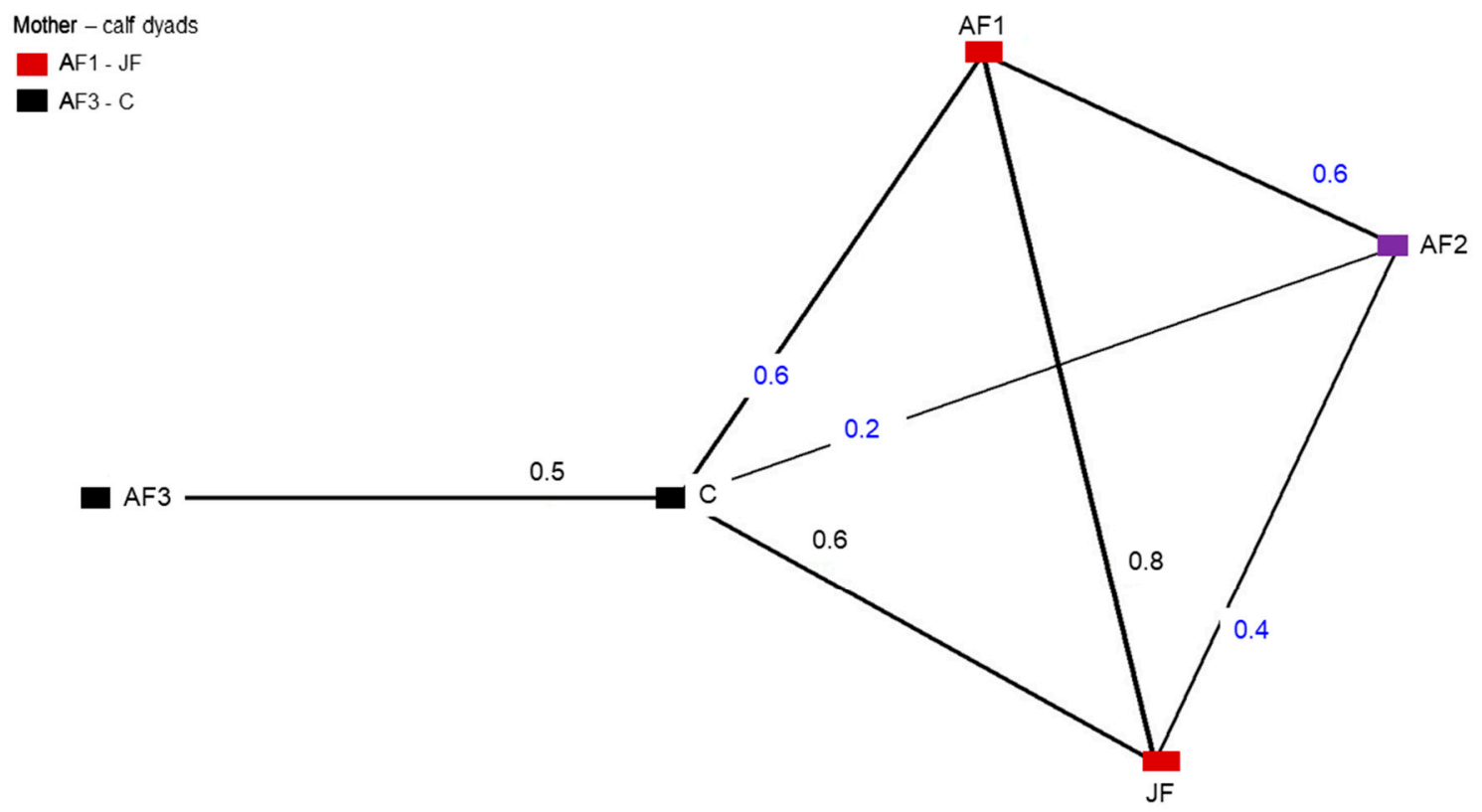

Figure 4. A sociogram highlighting the extent of association between study subjects, using only lying rest data, when individuals were either touching or within one elephant body length of a conspecific. Only associations $\geq 0.1$ were shown on the sociogram for clarity. Matching node colours indicate a mother-calf dyad. Blue font denotes the extent of association between an unrelated dyad. Black font denotes the extent of association between a related dyad.

\section{Discussion}

Our study outlined how camera technology can be used to observe zoo housed individuals during times of limited staff and visitor presence. We highlight the importance of using known species-specific behavioural indicators of welfare to allow for a comprehensive evaluation of well-being on an individual basis. We present and discuss individual activity budgets for our study group. Additionally, we highlight our study individuals engage most in lying rest between the hours of 22:01 and 04:00. Furthermore, the time spent resting by our study group was not found to be influenced by seasonality. We add to the body of work that outlines the importance of social compatibility within zoo housed groups of elephants, showing that our study individuals form strong associations with each other during rest. These highly associated dyads include mothers and calves as well as unrelated individuals which have been housed together for an extended period. Due to the small sample size for this study, the authors have treated each day as the experimental unit within statistical analyses and have accepted pseudoreplication. In consequence, we highlight that our results may not be applicable to the wider population of zoo housed Elephas maximus. Therefore, we discuss our results in the context of our study group, with suggestions and directions for further study for other elephant holders.

\subsection{Activity Budgets}

Activity budgets are a useful tool in outlining how individuals choose to spend their time within their environment [25]. Historically, activity budgets outside of visitor and staff hours have been difficult to obtain for zoo housed individuals [4]. However, following investment in monitoring equipment by elephant holders and further research into behavioural indicators of welfare for this species [7], accurate and robust behavioural data can now be collected, particularly over the nocturnal period. Our results outline that in the hours between 16:00 and 10:00, all individuals spend the most time feeding and resting irrespective of age group. Feeding represented the majority of the activity budget for our study group, with individuals feeding on average for $57.7 \%$ (range $37.9 \%-68.2 \%$ ) of their nocturnal activity budget. Studies on feeding behaviour on both wild and captive elephants mainly report daylight feeding hours. However, Sukumar [26] reported wild 
Asian elephants may spend up to $16 \mathrm{~h}$ a day feeding or foraging whilst wild savannah elephants were outlined to spend as much as $74 \%$ of their total time budget feeding [27]. Whilst direct comparisons with these studies are not achievable, we can suggest that the majority of a wild elephants' time budget is spent feeding, a trend observed in our study. Resting was also found to represent a high proportion of individuals' activity budgets with an average time spent resting calculated to be $28.2 \%$ (range $22.9 \%$ to $35.1 \%$ ) of the data collection period. In previous published work, we highlighted that the duration of time our study subjects spent resting was in line with another large European institution [22]. In addition, we outlined that the majority of time resting for of our study individuals was spent in lying rest [22], a suggested positive welfare indicator for this species [7]. Engagement in other species-specific behaviour was recorded throughout our study, with all individuals observed to engage in affiliative social behaviour and self-maintenance behaviours. Furthermore, we report no bouts of agonistic social or stereotypic behaviour during our data collection period. Participation in species-appropriate behaviour has been suggested as a potential indicator that an individual is experiencing a good state of wellbeing $[28,29]$, with several species-specific behaviours being used as indicators of positive welfare for zoo housed elephants [7]. Stereotypies are the most frequently used behavioural measure of welfare for elephants [7] and whilst their use as a sole indicator of welfare experience should be treated with caution [30], their absence or reduction within an activity budget is usually correlated with positive welfare experience [30-33]. We suggest that the quantification of individual activity budgets, particularly during hours of limited visitor or staff present, can provide a more holistic and comprehensive evaluation of wellbeing using multiple species-specific behavioural indicators of welfare.

\subsection{Resting Times}

Engagement in resting behaviour is known to be fundamental for growth, development and regeneration across the animal kingdom [34-37]. However, there have been relatively few studies that have investigated the resting behaviour of elephants housed in UK zoos [7,20,38]. Despite this lack of research, elephant holders have suggested that the quality and pattern of resting behaviour of zoo housed elephants should be an area of research focus due to its potential indication of welfare status [39]. In line with other published works, our data collection window was split into three time periods [20] and we documented engagement in both standing and lying forms of rest. Our findings were consistent with that of other studies $[20,38,40,41]$, with individuals spending the majority of their time in lying rest between the hours of 22:01 and 04:00. However, the time that individuals spent in standing rest did not significantly differ across the three time periods. In consequence, based on consistent findings with other published works, it could be recommended that future studies evaluating lying rest in zoo housed elephants could direct their observations towards the hours of 22:01-04:00, to maximise resource if time was limited. However, if standing rest was the behaviour of interest it may be recommended that researchers observe the whole night of footage to gain a comprehensive understanding. Studies on resting behaviour on wild elephants are limited; however, Gravett et al. [42] reported wild African females to have an average daily sleep time of two hours, mostly between the hours of 02:00 and 06:00. Wild individuals were observed to only exhibit recumbent rest every third or fourth day, possibly due to potential poaching or predation events, suggesting that individuals will only lie down to rest when they feel comfortable and secure within their environment [31]. In consequence, whilst further work is required to directly correlate resting behaviour with welfare status, highlighting patterns of resting behaviour consistent with those found in other studies is a useful step towards increasing understanding the relationship between rest and wellbeing in zoo housed elephants.

\subsection{Seasonal Influences on Rest}

Seasonality is something that drives behaviour change in many mammalian species [43-45], due to changes in temperature and availability of resources [46]. When 
evaluating resting behaviour in this study, individuals were not found to significantly differ their total time spent resting between the two seasons. This result may be due to the consistency of the indoor housing environment experienced by our study subjects, with no changes in housing temperature or resources throughout the data collection period.

\subsection{Relationship between Number of Rest Bouts and Total Time Resting}

Few studies examine the relationship between the number of resting bouts and the total time that individuals spend resting in zoo housed elephants. Standing and recumbent resting bouts have been observed in wild elephants [47] but the accurate proportions of each have not been quantified to date. Our findings are consistent with Williams et al. [20], that the duration of time spent in rest is positively correlated with the number of observed resting bouts, when in both standing and lying rest. In addition, the amount of time that our study individuals spent in lying rest was negatively correlated with the total time that individuals engaged in standing rest. In consequence, our work can suggest a theory that each individual has a total rest allocation per night, the proportions of which are divided into standing and lying rest. As such, this proportion of standing vs. lying rest could be used as an additional measure in the longitudinal evaluation of individual welfare. In their systematic review to identify welfare indicators for this species, Williams et al. [7] outline that there may be an optimal level of rest for individuals, but further work needs to be done to understand the relationship between recumbence and rest from a welfare perspective. Studies have outlined that recumbence behaviour is inversely related to age for both African and Asian elephants, with Holdgate et al. [38] also identifying that recumbence behaviour was highest in individuals which had access to the largest amount of outdoor space overnight. Chadwick et al. [39] outline that from the perspective of zoo staff, individuals not lying down to rest is an indication of negative welfare; however, excessive recumbent bout lengths for individuals could also be a suggestion of suboptimal welfare experience [7]. As such, we cannot definitively state the correlations between standing and lying rest bouts observed in this study are an indication of positive welfare, more that the documentation of this information can be used alongside other welfare indicators over time to gain a more comprehensive understanding of welfare experience on an individual basis.

\subsection{Social Aspects of Resting Behaviour}

Appropriate social groupings have been highlighted as one of the most important factors in determining the success of keeping Asian elephants in a positive welfare state within a zoo setting $[19,48,49]$. Elephant holders are now striving to replicate social environments which reflect that of wild individuals, aiming to keep herds formed of multiple highly related matrilines, led by a matriarch [22]. Affiliative social relationships between group members are thought to contribute strongly to overall group cohesion and stability and as such are used as indicators of positive welfare [7]. Previous study has reported that social variables have a strong association with time spent in lying rest [38], with Williams et al. [20] reporting that individuals were found to have longer resting bouts when a conspecific was within a distance of two elephant body lengths. However, in groups of mixed age-classes some individuals were found to rest less due to disturbance from younger individuals [50]. In addition to social structure, social compatibility can also influence time spent resting, with Evison et al. [51] highlighting that following the translocation of a socially incompatible female to another facility, duration of time spent in recumbent rest increased for the remaining group members.

Results from our study outline that our subjects chose to spend the majority of their time resting in social proximity of other individuals. Three individuals "AF2", "JF" and " $\mathrm{C}$ " chose to rest exclusively within two body lengths of conspecifics throughout our data collection period.

When evaluating the extent of association between individuals, we found that mothers and calves were highly associated when engaging in rest behaviour. Additionally, we found 
" $\mathrm{C}$ " the youngest individual within our study to be highly associated with half-sister "JF", a dyad which could be extremely important in the development and facilitation of social behaviour [52,53]. Using the Index of Association score, we highlight the key role that " $\mathrm{C}$ " plays in connecting her dam "AF3" to the core female group, particularly in lying rest (Figures 3 and 4). In consequence, the role that calves and juveniles could play in encouraging and facilitating positive social relationships within breeding groups should not be overlooked.

Species-specific zoo legislation [54] now outlines that breeding collections should aim to keep stable matriarchal herds wherever possible, comprising of four compatible females over two years old. However, Williams et al. [55] emphasise that unrelated elephants can still form appropriate and successful social groupings with conspecifics. We present information from our study that supports this statement, highlighting that unrelated female "AF2" forms meaningful associations with other group members when resting. "AF1" and "AF2" have been housed in the same facility for over 30 years, moved to the UK in the same import from a logging camp in Myanmar. This dyad was found to be highly associated throughout our study. As a result, we outline that the time that individuals have been housed together could be an important factor to consider when evaluating herd structure and potential animal transfers as part of the species breeding programme. Our results show the importance of monitoring social relationships and overall compatibility of individuals within breeding groups, both to document compliance with outlined legislation and to use as an indicator of positive welfare experience.

As technology advances and becomes cheaper and more accessible, observing elephants during hours of limited staff and visitor presence will become more practically achievable globally. Methods described in this paper could be repeated to observe 24-h time budgets of other elephants under human care, to globally benefit zoo elephant welfare. As described by Fernandez and Timberlake [56] and Maple and Segura [57], improved collaborations between elephant holding zoos should be explored, using standardized shared methodologies to widen the dataset and enable broader academic collaborations. Using student research assistants to collect these data, the dataset could be further extended cost effectively, for meaningful future comparison between individuals experiencing different zoo situations, leading to individual welfare improvement. Additionally, within a single institution such as ZSL Whipsnade Zoo, repeating these methods over the long lifespan of an individual elephant will enable more extensive longitudinal welfare assessment and therefore welfare improvement throughout the animals' life.

Author Contributions: Conceptualization, K.F., F.S. and L.J.R.; methodology, K.F., L.J.R.; software, K.F.; formal analysis, K.F.; investigation, K.F., F.S. and L.J.R.; resources, F.S., L.J.R., M.F.; data curation, K.F.; writing - original draft preparation, K.F., F.S. and L.J.R.; writing-review and editing, K.F., F.S., M.F. and L.J.R.; visualization, K.F.; supervision, L.J.R., F.S.; project administration, L.J.R.; funding acquisition, F.S., M.F., L.J.R. All authors have read and agreed to the published version of the manuscript.

Funding: This research received no external funding.

Institutional Review Board Statement: This research has been approved through the ZSL zoo research review process (reference number ZDZ104).

Informed Consent Statement: Not applicable.

Data Availability Statement: The data presented in this study are available on request from the corresponding author.

Acknowledgments: The authors would like to extend particular thanks to the keeping team of the Whipsnade Zoo elephant section. Without their constant support throughout the research process, it would not have been possible to formalize a successful research program. Similar thanks also go to the animal management team at ZSL for the support and allocation of funds to facilitate this period of data collection.

Conflicts of Interest: The authors declare no conflict of interest. 


\section{Appendix A}

Table A1. Ethogram; state behaviour definitions.

\begin{tabular}{|c|c|c|}
\hline Behaviour Category & Behaviour & Description \\
\hline Anticipatory & Anticipatory & $\begin{array}{l}\text { Individual stands in a stationary, quadrupedal position at a fixed point } \\
\text { within the exhibit. Attention is often fixed at this point, with head } \\
\text { orientated towards it and no other discernible behaviours taking place. }\end{array}$ \\
\hline Feeding & Feeding & $\begin{array}{l}\text { Active consumption or manipulation of feed items or ingestion of water. } \\
\text { Includes foraging for grass, browse and hay and consumption of pellet feed. }\end{array}$ \\
\hline Locomotion & Walk & $\begin{array}{l}\text { Individual moving across the enclosure at a walking pace. Only one foot is } \\
\text { removed from the ground at any one time. }\end{array}$ \\
\hline Locomotion & Run & $\begin{array}{l}\text { Individual moving across the enclosure at a running pace, more than one } \\
\text { foot is removed from the ground at any one time. }\end{array}$ \\
\hline Maintenance & Digging & Individual using foot to displace substrate. \\
\hline Maintenance & Dust bathing & $\begin{array}{l}\text { Individual uses trunk to pick up sand, dust or other substrate and throw it } \\
\text { over the body. }\end{array}$ \\
\hline Maintenance & Grooming self & $\begin{array}{l}\text { Individual is scratching or rubbing itself using trunk or against an } \\
\text { enclosure furnishing. }\end{array}$ \\
\hline Other & Affiliative social behaviour & $\begin{array}{l}\text { Any social behaviour which maintains or strengthens positive social } \\
\text { relationships within the group. }\end{array}$ \\
\hline Other & Agonistic social behaviour & $\begin{array}{l}\text { Individuals interacting in a way which may disrupt or weaken social bonds } \\
\text { within the group. }\end{array}$ \\
\hline Other & Enrichment manipulation & $\begin{array}{l}\text { Interaction with pieces of enrichment provided by the keepers as part of } \\
\text { their enrichment plan. }\end{array}$ \\
\hline Other & Keeper interaction & $\begin{array}{l}\text { Any interaction between the individual and members of the animal } \\
\text { keeping team. }\end{array}$ \\
\hline Other & Object manipulation & Interaction with other objects within the enclosure other than enrichment. \\
\hline Resting & Lying rest & Individual is relaxed in lateral recumbence. \\
\hline Resting & Standing rest & $\begin{array}{l}\text { Individual is upright and stationary with } 3 \text { or } 4 \text { feet on the ground, trunk is } \\
\text { relaxed and eyes usually closed. Individual is relaxed with no other } \\
\text { behaviour being displayed. }\end{array}$ \\
\hline
\end{tabular}

\section{References}

1. Sherwen, S.L.; Hemsworth, L.M.; Beausoleil, N.J.; Embury, A.; Mellor, D.J. An animal welfare risk assessment process for zoos. Animals 2018, 3, 130. [CrossRef] [PubMed]

2. Mellor, D.J. Updating animal welfare thinking: Moving beyond the "five freedoms" towards "a life worth living". Animals 2016, 6, 21. [CrossRef] [PubMed]

3. Kagan, R.; Carter, S.; Allard, S. A Universal animal welfare framework for zoos. J. Appl. Anim. Welf. Sci. 2015, 18, S1-S10. [CrossRef]

4. Harris, M.; Sherwin, C.; Harris, S. The Welfare, Housing and Husbandry of Elephants in UK Zoos. DEFRA Science and Research Project WC05007; Department of Food, the Environment and Rural Affairs: London, UK, 2008.

5. Clubb, R.; Mason, G. A Review of the Welfare of Zoo Elephants in Europe. A Report Commissioned by the RSPCA; University of Oxford: Oxford, UK, 2002.

6. Brown, J.L.; Carlstead, K.; Bray, J.D.; Dickey, D.; Farin, C.; Ange-van Heugten, K. Individual and environmental risk factors associated with fecal glucocorticoid metabolite concentrations in zoo-housed Asian and African elephants. PLoS ONE 2019, 14, e0217326. [CrossRef] [PubMed]

7. Williams, E.; Chadwick, C.L.; Yon, L.; Asher, L. A review of the current indicators of welfare in captive elephants (Loxodonta africana and Elephas maximus). Anim. Welf. J. 2018, 27, 235-249. [CrossRef]

8. Carlstead, K.; Paris, S.; Brown, J.L. Good keeper-elephant relationships in North American zoos are mutually beneficial to welfare. Appl. Anim. Behav. Sci. 2011, 211, 103-111. [CrossRef]

9. Edwards, K.L.; Miller, M.A.; Carlstead, K.; Brown, J.L. Relationships between housing and management factors and clinical health events in elephants in North American zoos. PLoS ONE 2017, 14, e0217774. [CrossRef]

10. Greco, B.J.; Meehan, C.L.; Hogan, J.N.; Leighty, K.A.; Mellen, J.; Mason, G.J.; Mench, J.A. The days and nights of zoo elephants: Using epidemiology to better understand stereotypic behaviour of African elephants (Loxodonta africana) and Asian elephants (Elephas maximus), in North American zoos. PLoS ONE 2016, 11, e0144276. [CrossRef] 
11. Prado-Oveido, N.A.; Bonaparte-Saller, M.K.; Malloy, E.J.; Meehan, C.L.; Mench, J.A.; Carlstead, K.; Brown, J.L. Evaluation of demographics and social life events of Asian (Elephas maximus) and African elephants (Loxodonta africana) in North American zoos. PLOS ONE 2016, 11, e0154750. [CrossRef]

12. Schulte, B.A. Social structure and helping behavior in captive elephants. Zoo Biol. 2000, 19, 447-459. [CrossRef]

13. Yon, L.; Williams, E.; Harvey, N.; Asher, L. Development of a behavioural welfare assessment tool for routine use with captive elephants. PLoS ONE 2019, 14, e0210783. [CrossRef]

14. Brando, S.; Buchanan-Smith, H.M. The 24/7 approach to promoting optimal welfare for captive wild animals. Behav. Process. 2018, 156, 83-95. [CrossRef] [PubMed]

15. Stokes, H.; Perera, V.; Jayasena, N.; Silva-Fletcher. Nocturnal behaviour of orphaned Asian elephant (Elephas maximus) calves in Sri Lanka. Zoo Biol. 2017, 36, 261-272. [CrossRef] [PubMed]

16. Dale, R.H.I. Birth statistics for (Loxodonta africana) and Asian (Elephas maximus) elephants in human care: History and implications for elephant welfare. Zoo Biol. 2010, 29, 87-103. [CrossRef] [PubMed]

17. Santymire, R.; Meyer, J.M.S.; Freeman, E.W. Characterising sleep behaviour of the wild black rhinoceros (Diceros bicornis bicornis). Sleep 2012, 35, 1569-1574. [CrossRef]

18. Lima, S.L.; Rattenborg, N.C.; Lesku, J.A.; Amlaner, C.J. Sleeping under the risk of predation. Anim. Behav. 2005, 70, 723-736. [CrossRef]

19. Meehan, C.L.; Mench, J.A.; Carlstead, K.; Hogan, J.N. Determining connections between the daily lives of zoo elephant and their welfare: An epidemiological approach. PLoS ONE 2016, 11, e0158124. [CrossRef]

20. Williams, E.; Bremner-Harrison, S.; Harvey, N.; Evison, E.; Yon, L. An investigation into resting behaviour in Asian elephants in UK zoos. Zoo Biol. 2015, 34, 406-417. [CrossRef]

21. Martin, P.R.; Bateson, P.P.G. Measuring Behaviour: An Introductory Guide, 3rd ed.; Cambridge University Press: Cambridge, UK, 2007.

22. Finch, K.; Sach, F.; Fitzpatrick, M.; Masters, N.; Rowden, L.J. Longitudinal improvements in zoo housed elephant welfare: A case study at ZSL Whipsnade Zoo. Animals 2020, 10, 2029. [CrossRef] [PubMed]

23. R Core Team. A Language and Environment for Statistical Computing; R Foundation for Statistical Computing: Vienna, Austria, 2013; Available online: http:/ / www.R-project.org (accessed on 24 November 2020).

24. Borgatti, S.P.; Everett, M.G.; Freeman, L.C. Ucinet 6 for Windows: Software for Social Network Analysis; Analytic Technologies: Harvard, MA, USA, 2002.

25. Mattachini, G.; Riva, E.; Provolo, G. The lying and standing activity indices of dairy cows in free-stall housing. Appl. Anim. Behav. Sci. 2011, 129, 18-27. [CrossRef]

26. Sukumar, R. Ecology of the Asian elephant in southern India. J. Trop. Ecol. 1990, 6, 33-53. [CrossRef]

27. Beekman, J.H.; Prins, H.H.T. Feeding strategies of sedentary large herbivores in East Africa, with emphasis on the African buffalo, Syncerus coffer. Afr. J. Ecol. 1989, 27, 129-147. [CrossRef]

28. Veasey, J.S. Assessing the psychological priorities for optimising captive Asian elephant (Elephas maximus) welfare. Animals 2020, 10, 39. [CrossRef]

29. Fernandez, E.J.; Yoakum, E.; Andrews, N. Seasonal and daily activity of two zoo housed grizzly bears (Ursus arctos horribilis). J. Zool. Bot. Gard. 2020, 1, 1-12. [CrossRef]

30. Mason, G.J.; Latham, N.R. Can't stop, won't stop: Is stereotypy a reliable animal welfare indicator? Anim. Welf. 2004, 13, 57-69.

31. Koyama, M.; Ueno, Y.; Equchi, Y.; Uetake, K.; Tanaka, T. Effects of daily management changes on behavioural patterns of a solitary female African elephant (Loxodonta africana). Anim. Sci. J. 2012, 83, 562-570. [CrossRef]

32. Greco, B.J.; Meehan, C.L.; Miller, L.J.; Shepherdson, D.J.; Morfeld, K.A.; Andrews, J.; Baker, A.M.; Carlstead, K.; Mench, J.A. Elephant management in North American zoos: Environmental enrichment, feeding, exercise and training. PLoS ONE 2016, 11, e0152490. [CrossRef] [PubMed]

33. Mellor, D.J. Operational details of the five domains model and its key applications to the assessment and management of animal welfare. Animals 2017, 7, 60. [CrossRef]

34. Plesch, G.; Broerkens, N.; Laister, S.; Winckler, C.; Knierim, U. Reliability and feasibility of selected measures concerning resting behaviour for the on-farm welfare assessment in dairy cows. Appl. Anim. Behav. Sci. 2010, 126, 19-26. [CrossRef]

35. Bejder, L.; Videsen, S.; Hermannsen, L.; Simon, M.; Hanf, D.; Madsen, P.T. Low energy expenditure and resting behaviour of humpback whale mother-calf pairs highlights conservation importance of sheltered breeding areas. Sci. Rep. $2019,9,711$. [CrossRef] [PubMed]

36. Tyne, J.; Johnston, D.W.; Rankin, R.; Loneragan, N.R.; Bejder, L. The importance of spinner dolphin (Stenella longirostris) resting habitat: Implications for management. J. Appl. Ecol. 2015, 52, 621-630. [CrossRef]

37. Llaneza, L.; Garcia, E.J.; Palacios, V.; Sazatornil, V.; Lopez-Bao, J.V. Resting in risky environments: The importance of cover for wolves to cope with exposure risk in human-dominated landscapes. Biodivers. Conserv. 2016, 25, 1515-1528. [CrossRef]

38. Holdgate, M.R.; Meehan, C.L.; Hogen, J.N.; Miller, L.J.; Rushen, J.; de Passillé, A.M.; Soltis, J.; Andrews, J.; Shepherdson, D.J. Recumbence behaviour in zoo elephants: Determination of patterns and frequency of recumbent rest and associated environmental and social factors. PLoS ONE 2016, 11, e0153301. [CrossRef] [PubMed]

39. Chadwick, C.L.; Williams, E.; Asher, L.; Yon, L. Incorporating stakeholder perspectives into the assessment and provision of captive elephant welfare. Anim. Welf. 2017, 26, 461-472. [CrossRef] 
40. Tobler, I. Behavioural sleep in the Asian elephant in captivity. Sleep 1992, 15, 1-12. [PubMed]

41. Kurt, F.; Garai, M.E. The Asian Elephant in Captivity: A Field Study; Cambridge University Press India Pvt. Ltd.: New Delhi, India, 2006.

42. Gravett, N.; Bhagwadin, A.; Sutcliffe, R.; Landen, K.; Chase, M.J.; Lyamin, O.I.; Siegel, J.M.; Manger, P.R. Inactivity/sleep in two wild free-roaming African elephant matriarchs-Does large body size make elephants the shortest mammalian sleepers? PLoS ONE 2007, 12, e0171903. [CrossRef]

43. Beck, C.A.; Bowen, W.D.; Iverson, S.J. Seasonal changes in buoyancy and diving behaviour of adult grey seals. J. Exp. Biol. 2000, 203, 2323-2330.

44. Linnane, M.I.A.; Bereton, J.; Giller, P.S. Seasonal changes in circadian grazing patterns of Kerry cows (Bos taurus) in semi-feral conditions in Killarney National Park, Co. Kerry, Ireland. Appl. Anim. Behav. Sci. 2001, 71, 277-292. [CrossRef]

45. Brent, L.J.; MacLarnon, A.; Platt, M.L.; Semple, S. Seasonal changes in the structure of rhesus macaque social networks. Behav. Evol. Sociobiol. 2013, 67, 349-359. [CrossRef]

46. Birkett, P.J.; Vanak, A.T.; Muggeo, V.M.R.; Ferreira, S.M.; Slotow, R. Animal perception of seasonal thresholds: Changes in elephant movement in relation to rainfall patterns. PLoS ONE 2012, 7, e38363.

47. McKay, G.M. Behavior and ecology of the Asiatic elephant in southeastern Ceylon. Smithsonian Contr. Zool. 1973, 12, 273-289. [CrossRef]

48. Schmidt, H.; Kappelhof, J. Review of the management of the Asian elephant Elephas maximus EEP: Current challenges and future solutions. Int. Zoo Yearb. 2019, 53, 31-44. [CrossRef]

49. Meehan, C.L.; Hogan, J.N.; Bonaparte-Saller, M.K.; Mench, J.A. Housing and social environments of African (Loxodonta Africana) and Asian (Elephas maximus) elephants on North American zoos. PLoS ONE 2016, 11, e0146703. [CrossRef]

50. Holdgate, M.R.; Meehan, C.L.; Hogan, J.N.; Miller, L.J.; Soltis, J.; Andrews, A.; Shepherdson, D.J. Walking behavior of zoo elephants: Associations between GPS-measured daily walking distances and environmental factors, social factors, and welfare indicators. PLoS ONE 2016, 11, e0150331. [CrossRef] [PubMed]

51. Evison, E.; McKenzie, A.; Holmes, L. Social and environmental impacts on sleep in captive Asian elephants (Elephas maxmius). Zoo Biol. 2020, 39, 397-404. [CrossRef]

52. Jayantha, D.; Dayawansa, P.N.; Padmalal, U.K.G.K.; Ratnasooriya, W.D. Social relationships of wild juvenile Asian elephants (Elephas maximus) in the Udawalawa National Park, Sri Lanka. JoTT 2009, 1, 211-214. [CrossRef]

53. Hartley, M.; Stanley, C. Survey of reproduction and calf rearing in Asian and African elephants in Europe. JZAR 2016, 4, 139-146.

54. Secretary of State's Standards of Modern Zoo Practice Appenidx 8-Specialist Exhibits, Elephants 2017. DEFRA: London, UK. Available online: https://www.gov.uk/government/uploads/system/uploads/attachment_data/file/69596/standards-of-zoopractice.pdf (accessed on 12 December 2020).

55. Williams, E.; Carter, A.; Hall, C.; Bremner-Harrison, S. Social interactions in zoo housed elephants: Factors affecting social relationships. Animals 2019, 9, 747. [CrossRef]

56. Fernandez, E.J.; Timberlake, W. Mutual benefits of research collaborations between zoos and academic institutions. Zoo Biol. 2008, 27, 470-487. [CrossRef]

57. Maple, T.L.; Segura, V.D. Advancing behavior analysis in zoos and aquariums. Behav. Anal. 2015, 38, 77-91. [CrossRef] 